\author{
مزَّان ويسى، مسعود شيدايى و فهيمه كوهدار

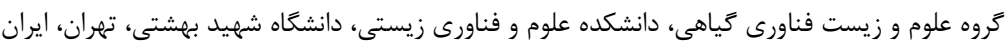 \\ مسئول مكاتبات: مزكان ويسى؛ mozhgan_veisi@yahoo.com
}

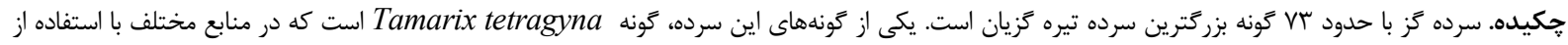

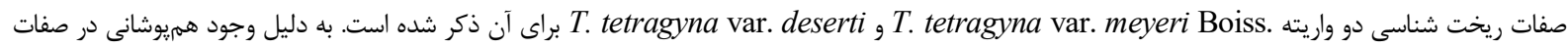

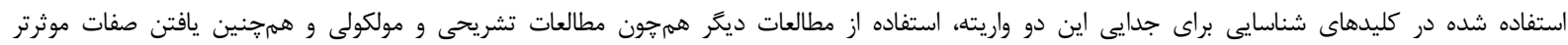

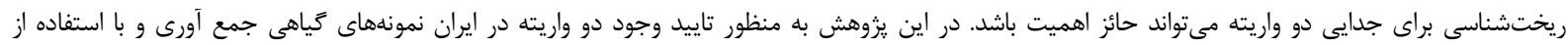

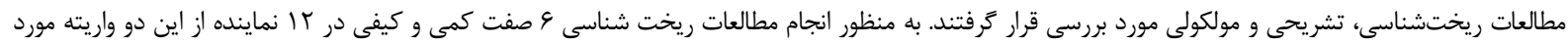

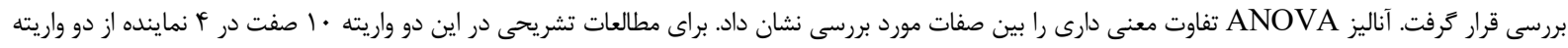

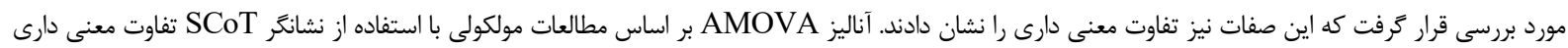

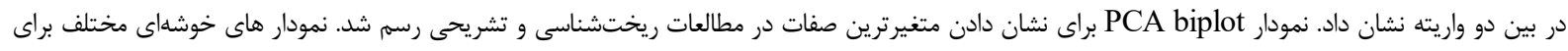

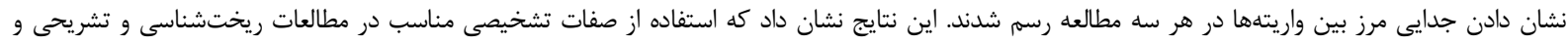

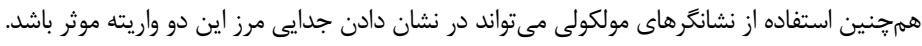

وازههاى كليدى. آرايه شناسى، جدايى واريتهها، صفات تشريحى، صفات ريختشناسى، SCoT

\title{
A morphological, anatomical and molecular study of two varieties of Tamarix tetragyna in Iran
}

\author{
Mozhgan Veisi, Masoud Sheidai \& Fahimeh Koohdar \\ Faculty of Life Sciences and Biotechnology, Shahid Beheshti University, Tehran, Iran \\ Correspondent author: Mozhgan veisi; mozhgan_veisi@yahoo.com
}

\begin{abstract}
Tamarix is the largest genus in the family Tamaricaceae with about 73 species. T. tetragyna var. meyeri and $T$. tetragyna var. deserti were previously reported from Iran. Due to the presence of overlapping features in the previously designed identification keys for the separation of these two varieties, it could be helpful to use other characters and character states derived from other sources, such as anatomical and molecular studies, in addition to find more effective morphological features for the separation of the two varieties. Therefore, the present study aimed to differentiate these two presumed varieties by multiple approaches using morphological, anatomical and molecular data. For morphological study, 6 quantitative and qualitative characters were examined in 12 samples of the two varieties. ANOVA analysis showed a significant difference between the studied characters. For anatomical study, 10 traits were examined in 4 samples of the two varieties, which also showed a significant difference. AMOVA analysis based on molecular studies using Scot marker showed a significant difference between the two varieties. The PCA biplot show the most variable traits in morphological and anatomical studies. For varieties delimitation, different clustering methods were drawn in all three studies. The results of this study showed that the use of appropriate diagnostic traits in morphological and anatomical studies as well as the use of molecular markers can be effective in showing the separated boundaries of the two varieties studied.
\end{abstract}

Key words. anatomical characters, morphological characters, SCoT, taxonomy, varieties delimitation 
سرده زز استفاده از نشانكرهاى مولكولى است ( Gaskin \&

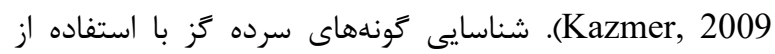

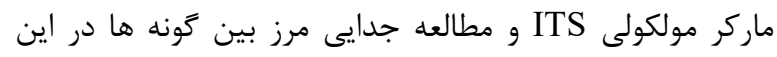

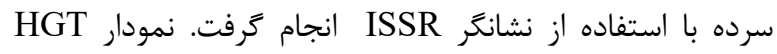

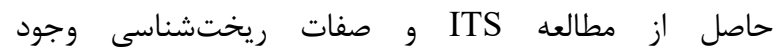
هيبريداسيون بين كونهاى سرده

.(Sheidai et al., 2019)

كونه .Tamarix tetragyna Ehrenb. يكى از كونههاى سرده

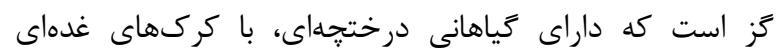

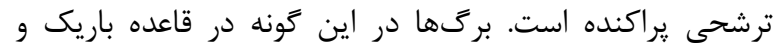

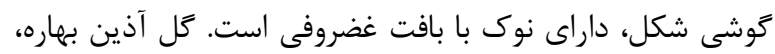

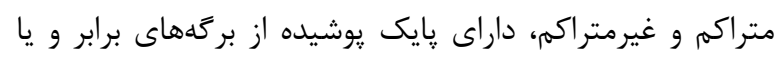
بلندتر از كاسه

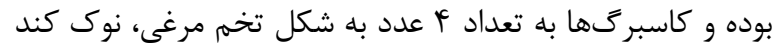

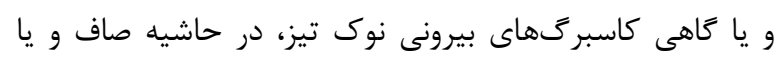

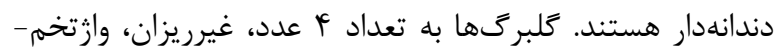

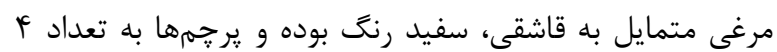

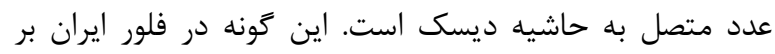

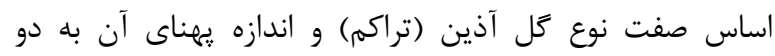

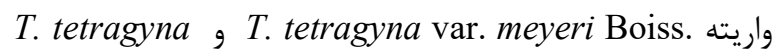
var. deserti

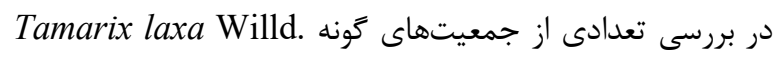
بر اساس صفاتريختى و تشريحى مشخص شد كه نه نهال نهاى اين

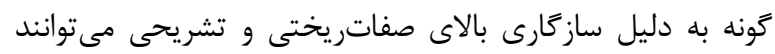

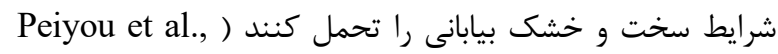

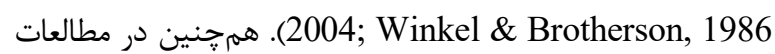

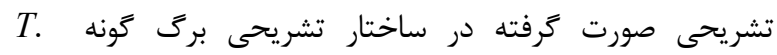
arborea var. arborea لايه ضخيم كوتيكول و موم يوشانده شدهاست كه نوعى سازكارى

مفيد با شرايط شورى است (Alaimo et al., 2013).

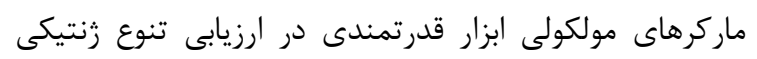

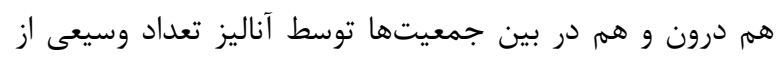
لوكوسهاى ثراكنده در زنوم است (Powell et al., 1996). تكنيكهاى مربوط به ماركرهاى زينتيك مولكولى نقش درم بسيار زيادى در تخمين و ارزيابى تنوع زنتيكى در مجموعههاى زنتيكي

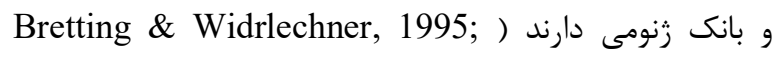

.(Brown \& Kresovich, 1996

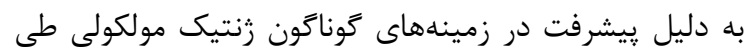

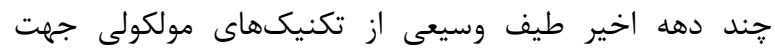

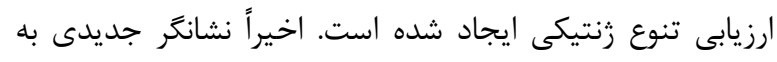

مقله تيره گزيان (Tamaricaceae) شامل r تا ه سرده و حدود

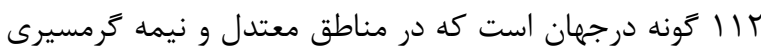

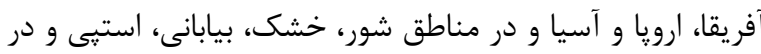

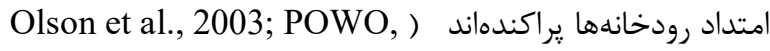
(2021

محدوده يراكنش سردهاى اين تيره در ايران در مناطق ايرانوتورانى و صحارا-سندى است (Gaskin, 2003; Baum, 1967).

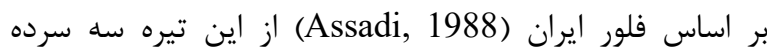

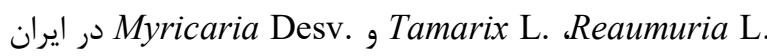
يافت مى شوند ) Ghahremaninejad et al., 2017; Gaskin كه بيشتر در كنار آبهاى جارى رودخانهها،

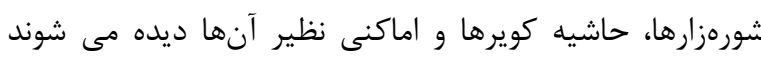
(Gaskin et al., 2003; Baum, 1967; Schiman, 1964) سهم عمده يراكنش اين تيره در ايران در استانهاى سيستان و

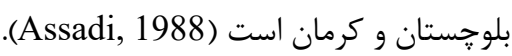

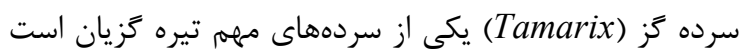

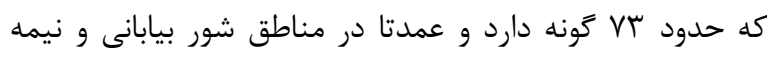

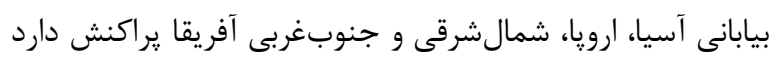
(Sheidai et al., 2018; POWO, 2021) طبيعى اين سرده در جنوب ارويا و از مسير خاورميانه به شمال

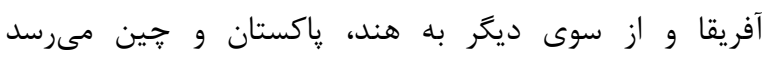

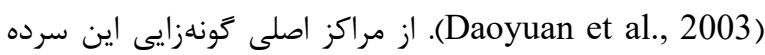

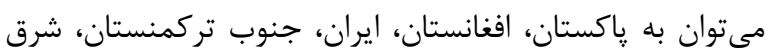
جين و نواحى شرقى مديترانه اشاره كرد.

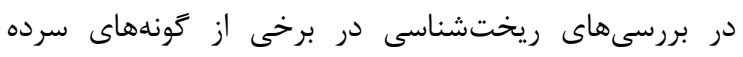
Tamarix

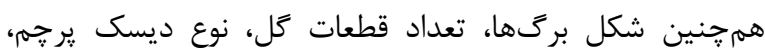

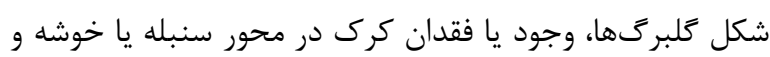

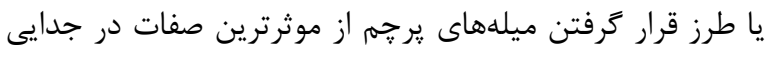
كونههاى اين سرده هستند (Arianmanesh et al., 2016).

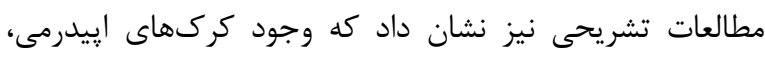

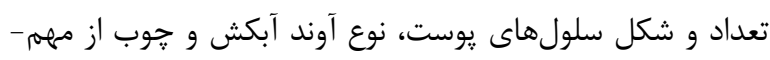

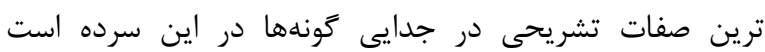
(Daoyuan et al., 2003)

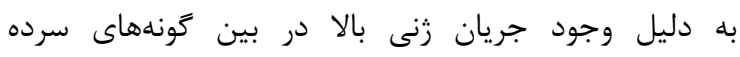
Tamarix

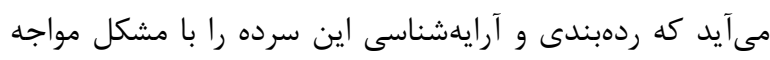

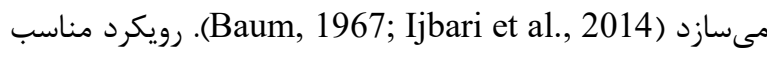
براى مطالعه نمونههاى حدواسط و هيبريد در بين گونهاى روناى 
مطالعات تشريحى نمونههاى گياه بالغ جداشده و بلافاصله در فرمالين-استيك

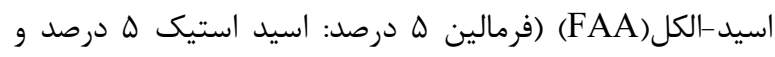
•ه درصد اتانول •و درصد) تثبيت زرديد (Jensen, 1962).

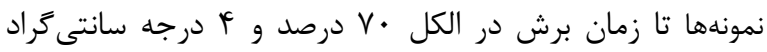
نكه داشته شدند. يس از تهيه مقاطع عرضى از نمونههاى برى

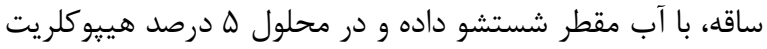

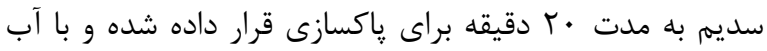

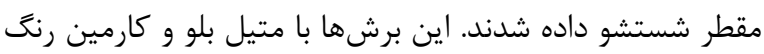

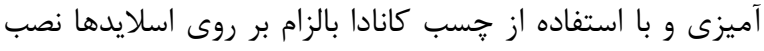

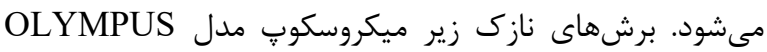
مشاهده شدند (Sheidai et al., 2006). صفات تشريحى ساقي هاقه و برگ در جدول r آورده شده است. در مطالعات تشريحى براى زروهبندى نمونهها از آز آناليز

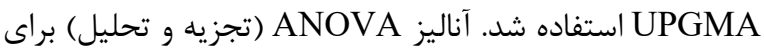
نشان دادن تفاوتهاى تشريحى بين افراد يك گونه انجام شد. در

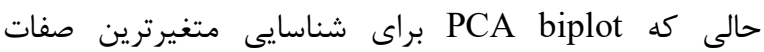
تشريحى در افراد مورد مطالعه استفاده شد (Podani, 2000).

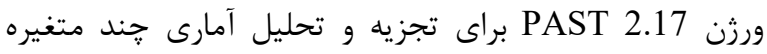
دادهها استفاده شد (Hammer et al., 2012). تجزئ

\section{مطالعات مولكولى}

بركهاى تازه جمع آورى شده در يودر زل سيليكازل خشك مشى

شدند، استخراج DNA زنومى با استفاده از زيروتكل ذغال فعال انجام شد (Sheidai et al., 2013). كيفيت و و كميت DNA و طيف سنج Nano Drop ارزيابى شد ( Križman et al.,

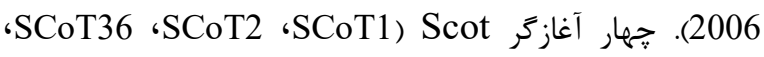
انتخاب شدند (SCoT41 يرايمرهاى مورد استفاده در واكنشهاى SCoT-PCR بهصورت خلاصه در جدول ب آورده شده است.

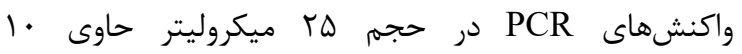

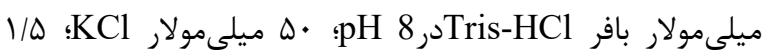

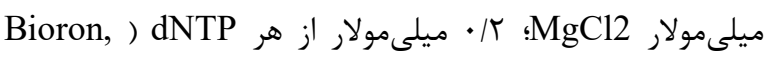
DNA Germany

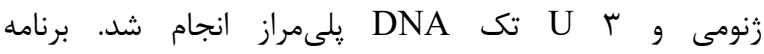
دمايى SCoT-PCR كه در آزمايشها مورد استفاده قرار گرفت به صورت خلاصه در جدول أ آورده شده است.

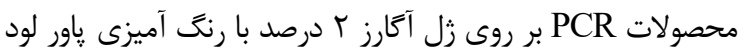

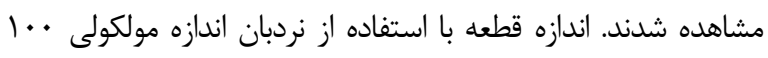
جفت باز (Lader) تخمين زده شد (Fermentas, Germany).
نام نشانگر Start Codon Targeted (SCoT) براى ارزيابى تنوع زنتيكى و تعيين مرز گونهها و فرم هاى يايين تر از سطح

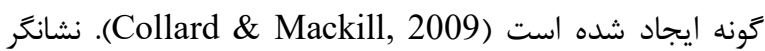
عموماً مبتنى بر نواحى حفاظت شده زنوم گياه است كه Sawant et al., ) احاطه شده است كدون شروع ATG

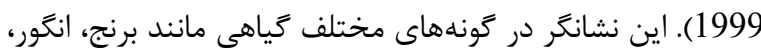
سيبزمينى، يرتقال، بادام زمينى و نيشكر و همرجنين نخل خرما استفاده شده است (Al-Qurainy et al., 2015). با استفاده از مطالعه خصوصيات ريختى و مولكولى در استى نمونههاى جمعآورى شده از استانهاى سيستان و بلوجستان،

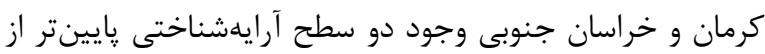
سطح گونه در گونه .Tamarix stricta Boiss نشان داده شد

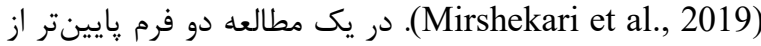
سطح گونه در زونه T. ramosissima با استفاده از صفات تشريحى، ريختى و مولكولى با ماركرهاى ISSR و ITS داده شد (Marefatyan et al., in press). به دليل وجود هميوشانى در صفات ريختشناسى در كليد شناسايى دو واريته گونه T. tetragyna، هدف از اين يزوهش تاييد وجود يا نبود دو واريته در اين گَونه در ايران با استفاده از

$$
\text { مطالعات ريخت شناسى، تشريحى و مولكولى است. }
$$

$$
\text { مواد و روش ها - ماه }
$$

مواد تياهى براى مطالعات ريختشناسى تشريحى \& نمونه و براى مطالعات مولكولى ه نمونه از دو واريته

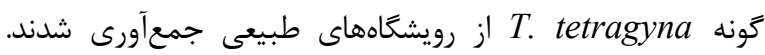

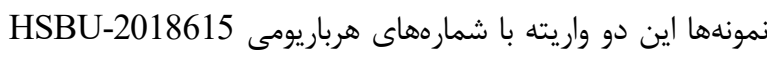

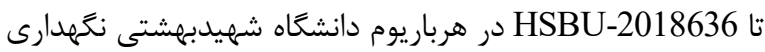

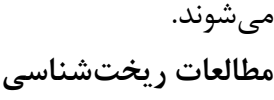

در مجموع \& صفت موثر در ريختشناسى (F كمى، ب كيفى)

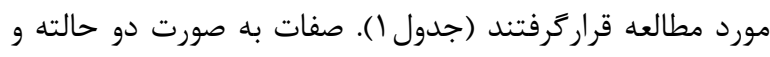
هند حالته كد كذارى شده است. آناليز ANOVA (تجزيه و تحليل) براى نشان دادن تفاوت ريختشناسى بين نماينده

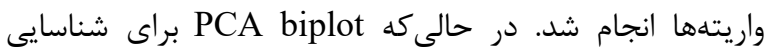
متغيرترين صفات ريختشناسى ميان افراد مورد مطالعه رسم شد (Podani, 2000). براى بررسى جدايى مرز بين واريتهها از آناليز خوشهاى Ward استفاده شد (Podani, 2000). تجزيه و تحليل برسي ونيل آمارى جند متغيره دادهها با استفاده از برنامه 2.17 PAST 2.17 انجام شد (Hammer et al., 2012). 
جدول ا- صفات ريخت شناسى مورد مطالعه در افراد كونه Tetragyna.

Table 1. Morphological characters studied in T. tetragyna.

\begin{tabular}{|l|l|l|}
\hline $\mathrm{N}$ & Character & State (code) \\
\hline 1 & Number of petals & $4(1), 5(2)$ \\
\hline 2 & Number of sepals & $4(1), 5(2)$ \\
\hline 3 & Number of stamen rows & One row (1),two rows(2) \\
\hline 4 & Outer sepal & Triangular(1),concave(2) \\
\hline 5 & Inner sepal & Triangular(1),concave(2) \\
\hline 6 & Number of stamen & $4(1), 5(2)$, more than5(3) \\
\hline
\end{tabular}

جدول r- صفات تشريحى مورد مطالعه ساقه و برى افراد گونه Tetragyna.

Table 2. Stem and leaf anatomical traits studied in T. tetragyna.

\begin{tabular}{|c|l|l|}
\hline $\mathrm{N}$ & Character & State (code) \\
\hline 1 & Length of stem epidermis to the entire stem & $0.01-0.03(1), 0.04-0.06(2)$ \\
\hline 2 & Cortex to cross section of stem & $0.05-0.14(1), 0.15-0.26(2)$ \\
\hline 3 & Stem sclerenchyma to stem cross section & $0.02-0.08(1)$ \\
\hline 4 & Number of stem vascular bundles & $4.9-6.7(1), 6.5-8.5(2), 8.6-9.9(3), 11-12(4)$ \\
\hline 5 & Type xylem & Discontinuous(1),Continuous(2) \\
\hline 6 & Type phloem & Continuous(2),Discontinuous $(1)$ \\
\hline 7 & How much does the leaf surround the stem & $3 / 4(1), 2 / 4(2), 1 / 4(3)$ \\
\hline 8 & Length of palisade parenchyma to the entire Leaf & $0.15-0.25(1), 0.26-0.32(2), 0.34-0.45(3)$ \\
\hline 9 & Number of leaf vascular bundles & $5-10(1), 11-15(2), 16-20(3), 20-25-26(4)$ \\
\hline 10 & Length of leaf epidermis to the entire Leaf & $0.07-0.12(1), 0.12-0.19(2)$ \\
\hline
\end{tabular}

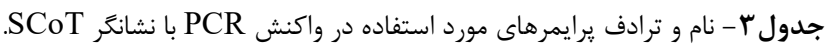

Table 3. Primers used in PCR reaction with SCoT marker.

\begin{tabular}{|l|l|l|}
\hline $\mathrm{N}$ & Primer & Sequence \\
\hline 1 & SCoT1 & 5'- CAACAATGGCTACCACCA -3' \\
\hline 2 & SCoT2 & 5'- CAACAATGGCTACCACCC-3' \\
\hline 3 & SCoT41 & 5' - CAATGGCTACCACTGACA-3' \\
\hline 4 & SCoT36 & 5'- GCAACAATGGCTACCACC-3' \\
\hline
\end{tabular}

جدول F - برنامه دمايى نشانكر SCoT استفاده در ارقام مورد مطالعه.

Table 4. SCoT marker temperature program used in the study of cultivars.

\begin{tabular}{|c|c|c|}
\hline Phase & Time and temperature & Number of cycles \\
\hline First denaturation & 4minutes at $94{ }^{\circ} \mathrm{C}$ & 1 \\
\hline Denaturation & 1 minutes at $94{ }^{\circ} \mathrm{C}$ & 40 \\
\hline Annealing & 1 minutes at $51^{\circ} \mathrm{C}$ & 40 \\
\hline Extension & 1 minutes at $72^{\circ} \mathrm{C}$ & 40 \\
\hline Final extension & 5 minutes at $72^{\circ} \mathrm{C}$ & 1 \\
\hline
\end{tabular}


است. طبق آناليز نمودار UPGMA افراد به دو كروه مجزا تفكيك شدند و اين نتايج مشابه نتيجه ريختشناسى است. در نمودار PCA biplot رسم شده مشخص شد. كه صن صفات

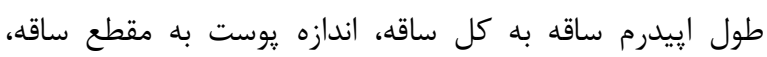

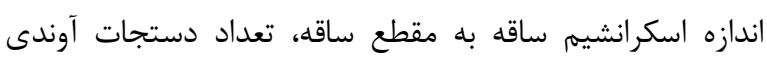

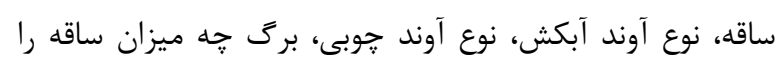

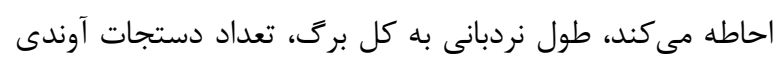

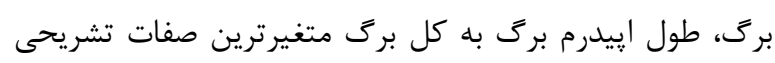

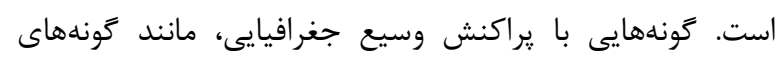

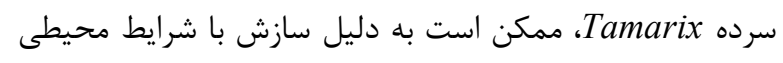

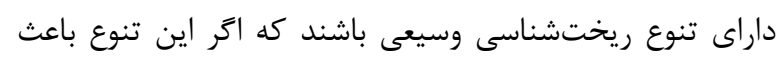

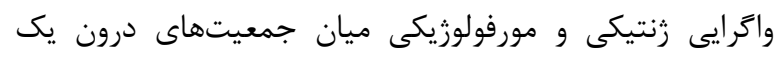

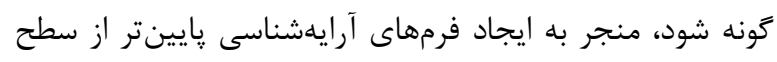

كونه مىشود (Sheidai et al., 2014). بسته به نوع تفاوتهاى ريختى ممكن است اكوتيبٍها، واريتهها

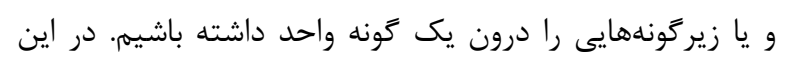

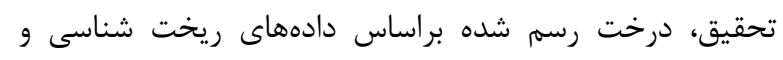

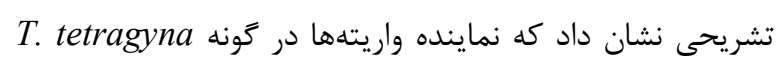

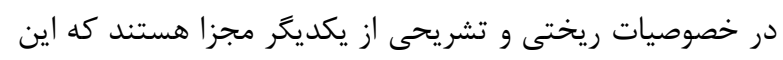

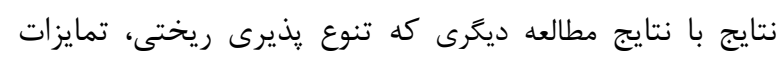

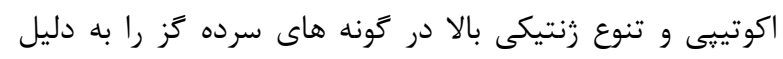

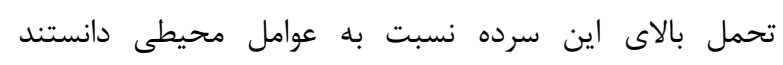

همخوانى دارد (Winkel \& Brotherson, 1986).
روش خوشهبندى (

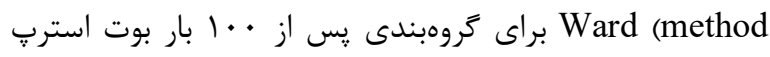

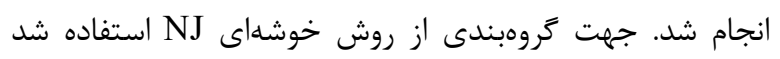

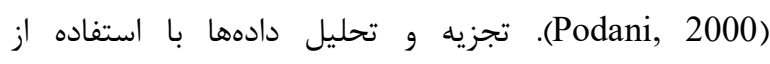

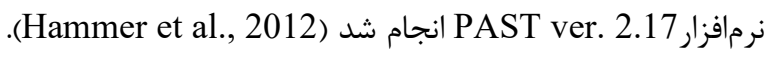
تست AMOVA جهت نشان دادن وجود تفاوت معنى دار در بين

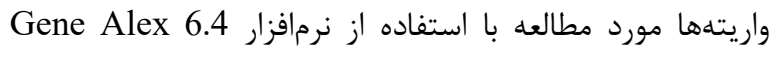
انجام كرفت (Peakall \& Smouse, 2006).

\section{نتايج \\ مطالعات ريختشناست}

T. Tتايج مطالعات ريختشناسى افراد مورد مطالعه در كَّنه tetragyna

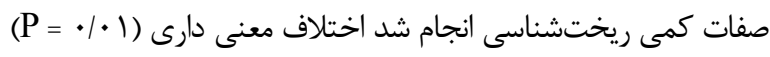

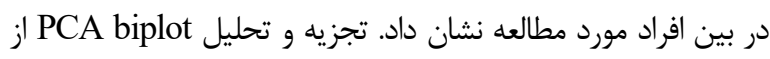
صفتهاى ريختشناسى نشان داد كه صفات تعداد يرجمه، اندازه بركانه

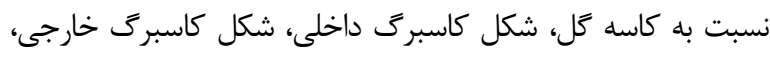

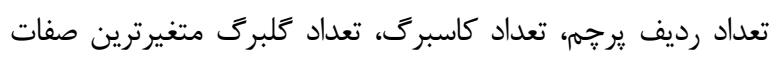

$$
\text { ريختشناسى است. }
$$

نمودار شاخهبندى Ward حاصل از مطالعات ريختشناسى رسم

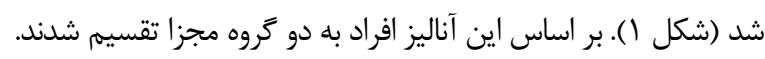

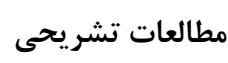
نتايج مطالعات تشريحى در ساقه و برى در افراد مورد مطالعاته

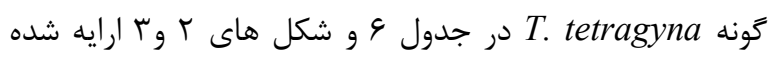

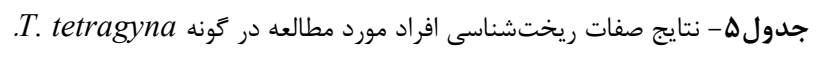

Table 5. Results of morphological traits in T. tetragyna.

\begin{tabular}{|c|c|c|c|c|c|c|}
\hline Sample & $\begin{array}{c}\text { Number } \\
\text { of petals }\end{array}$ & $\begin{array}{c}\text { Number } \\
\text { of sepals }\end{array}$ & $\begin{array}{c}\text { Number of } \\
\text { stamen rows }\end{array}$ & $\begin{array}{c}\text { Outer sepal } \\
\text { shape }\end{array}$ & $\begin{array}{c}\text { Inner sepal } \\
\text { shape }\end{array}$ & $\begin{array}{c}\text { Number of } \\
\text { stamen }\end{array}$ \\
\hline T. tetragyna & 5 & 5 & 1 & Concave & Triangular & 5 \\
\hline T. tetragyna & 5 & 5 & 1 & Concave & Triangular & 5 \\
\hline T. tetragyna & 5 & 5 & 1 & Concave & Triangular & 5 \\
\hline T. tetragyna & 5 & 5 & 1 & Triangular & Triangular & 5 \\
\hline T. tetragyna & 5 & 5 & 1 & Concave & Triangular & 5 \\
\hline T. tetragyna & 5 & 5 & 1 & Concave & Triangular & 5 \\
\hline T. tetragyna & 4 & 4 & 3 & Triangular & Concave & 4 \\
\hline T. tetragyna & 4 & 4 & 3 & Triangular & Concave & 4 \\
\hline T. tetragyna & 4 & 4 & 3 & Triangular & Concave & 4 \\
\hline T. tetragyna & 4 & 4 & 3 & Triangular & Concave & 4 \\
\hline T. tetragyna & 4 & 4 & 3 & Triangular & Concave & 4 \\
\hline T. tetragyna & 4 & 4 & 3 & Triangular & Concave & 4 \\
\hline
\end{tabular}




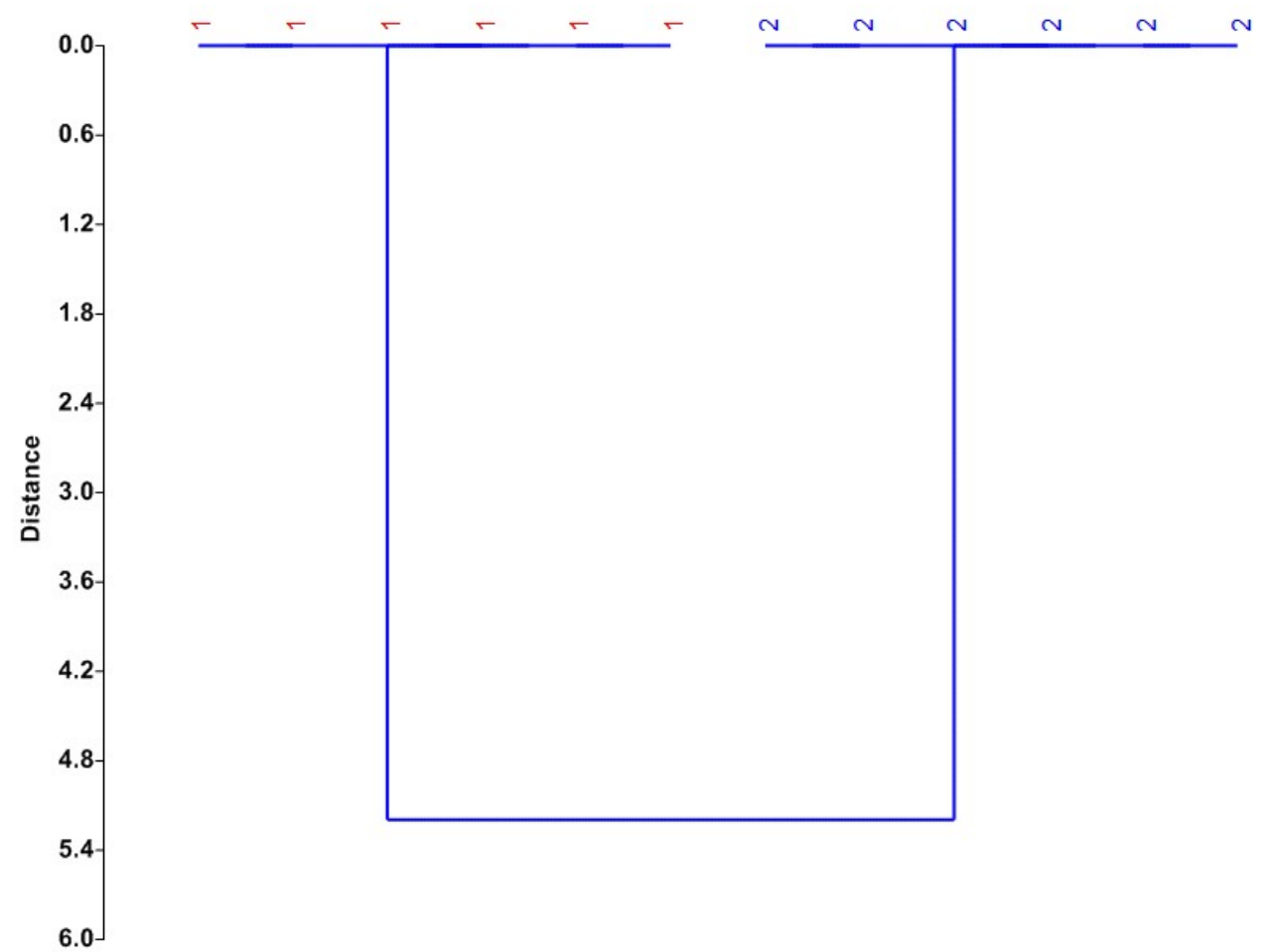

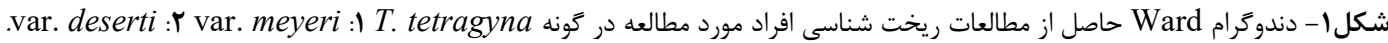

Figure 1. Ward dendrogram from morphological traits studied in T. tetragyna 1: var. meyeri 2: var. deserti.

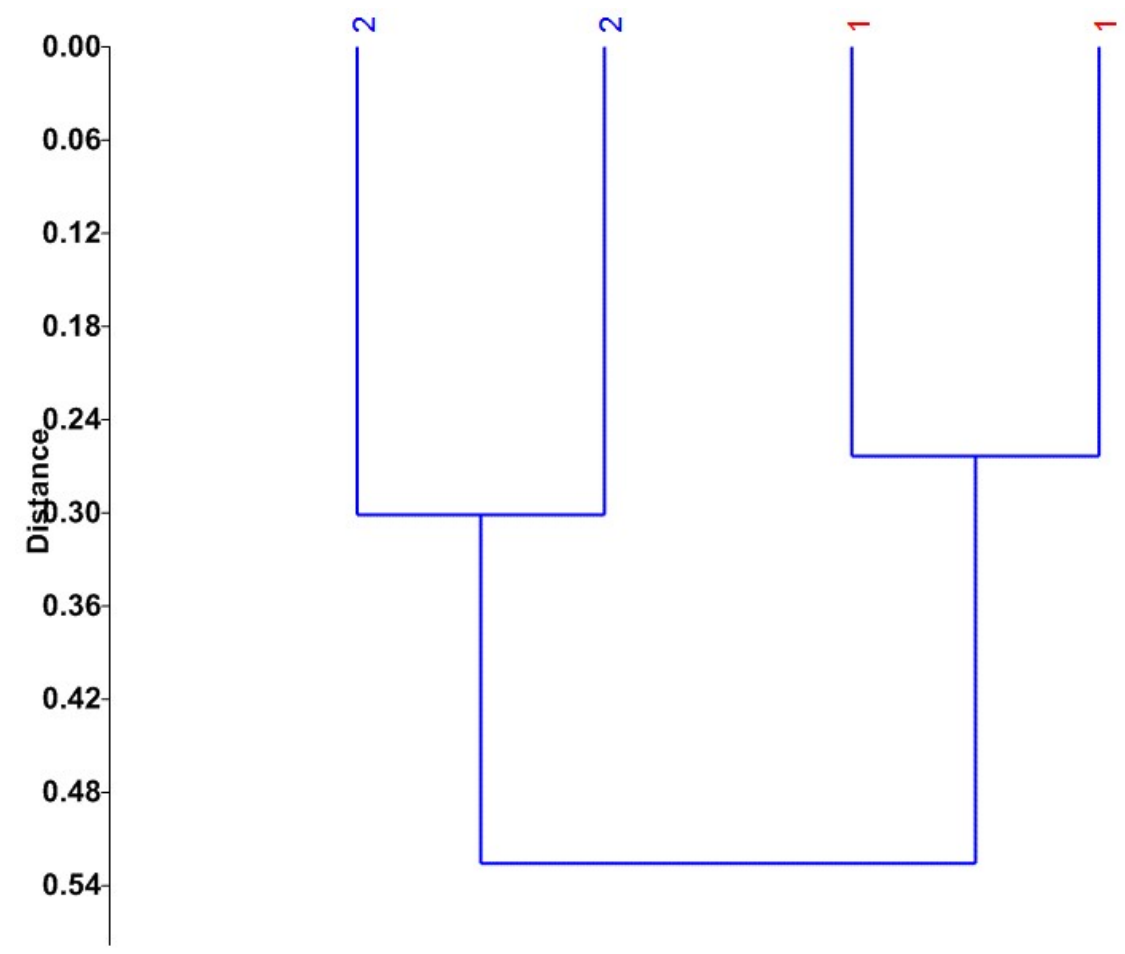

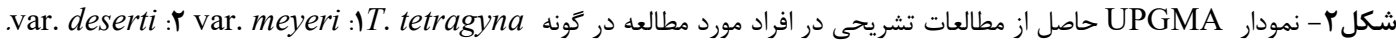

Figure 2. UPGMA dendogram of Anatomical features studied in T. tetragyna 1: var. meyeri 2: var. deserti. 
جدول 9- نتايج صفات تشريحى مورد مطالعه درساقه و برى افراد كونه T. tetragyna.

Table 6. Stem and leaf anatomical features studied in T. tetragyna.

\begin{tabular}{|c|c|c|c|c|}
\hline Sample & $\begin{array}{c}\text { length of } \\
\text { stem } \\
\text { epidermis } \\
\text { to the } \\
\text { entire } \\
\text { stem }\end{array}$ & $\begin{array}{c}\text { cortex } \\
\text { to } \\
\text { cross } \\
\text { section } \\
\text { of } \\
\text { stem }\end{array}$ & $\begin{array}{c}\text { Stem } \\
\text { sclerenchyma } \\
\text { to stem cross } \\
\text { section }\end{array}$ & $\begin{array}{c}\text { Number } \\
\text { of stem } \\
\text { vascular } \\
\text { bundles }\end{array}$ \\
\hline T. tetragyna & 0.03 & 0.18 & 0.08 & 7 \\
\hline T. tetragyna & 0.04 & 0.17 & 0.05 & 6 \\
\hline T. tetragyna & 0.009 & 0.06 & 0.01 & 11 \\
\hline T. tetragyna & 0.02 & 0.09 & 0.03 & 9 \\
\hline
\end{tabular}

جدول 9 (ادامه) - نتايج صفات تشريحى مورد مطالعه درساقه و برى افراد كونه Tetragyna. tetragya

Table 6 (Continues). Stem and leaf anatomical features studied in T. tetragyna.

\begin{tabular}{|c|c|c|c|c|c|c|}
\hline Sample & Type xylem & Type phloem & $\begin{array}{c}\text { How } \\
\text { much } \\
\text { does the } \\
\text { leaf } \\
\text { surround } \\
\text { the stem }\end{array}$ & $\begin{array}{c}\text { length of } \\
\text { palisade } \\
\text { parenchyma } \\
\text { to the } \\
\text { entire Leaf }\end{array}$ & $\begin{array}{c}\text { Number } \\
\text { of leaf } \\
\text { vascular } \\
\text { bundles }\end{array}$ & $\begin{array}{c}\text { length of } \\
\text { leaf } \\
\text { epidermis } \\
\text { to the } \\
\text { entire } \\
\text { Leaf }\end{array}$ \\
\hline T. tetragyna & Continuous & Discontinuous & $3 / 4$ & 0.34 & 18 & 0.12 \\
\hline T. tetragyna & Continuous & Continuous & $2 / 4$ & 0.22 & 12 & 0.12 \\
\hline T. tetragyna & Continuous & Continuous & $1 / 4$ & 0.21 & 10 & 0.10 \\
\hline T. tetragyna & Discontinuous & Continuous & $1 / 4$ & 0.27 & 26 & 0.14 \\
\hline
\end{tabular}

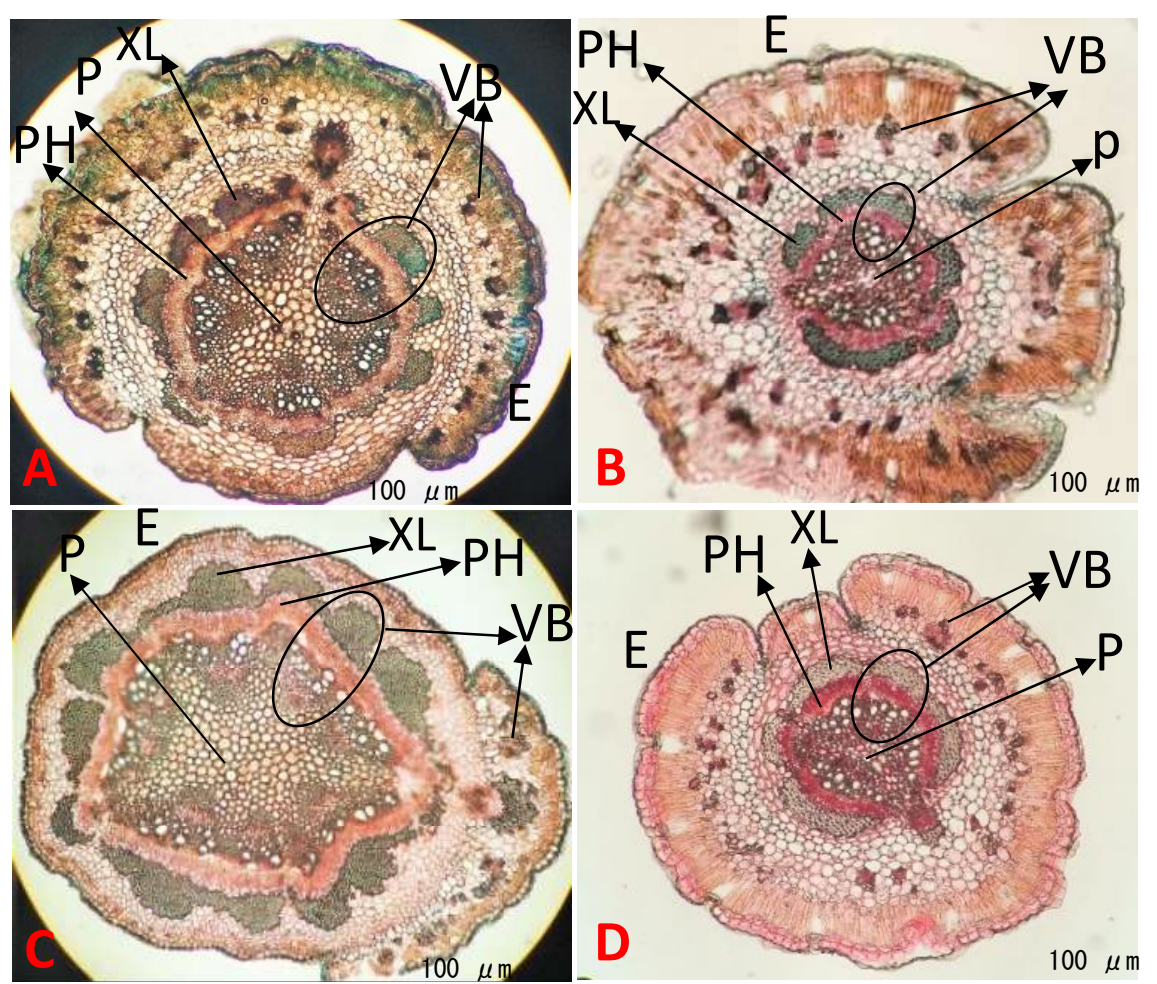

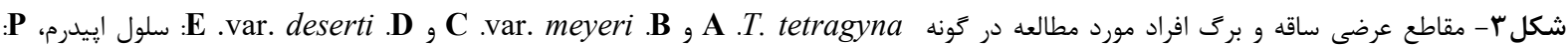

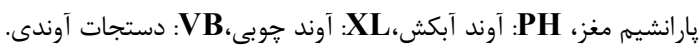

Figure 3. Transverse sections of the stem and leaf of $T$. tetragyna $\mathbf{A}$ and B. var. meyer. $\mathbf{C}$ and D. var. deserti. E: epidermal cell, P: pith parenchyma, PH: phloem, XL: xylem, VB: vascular bundle. 


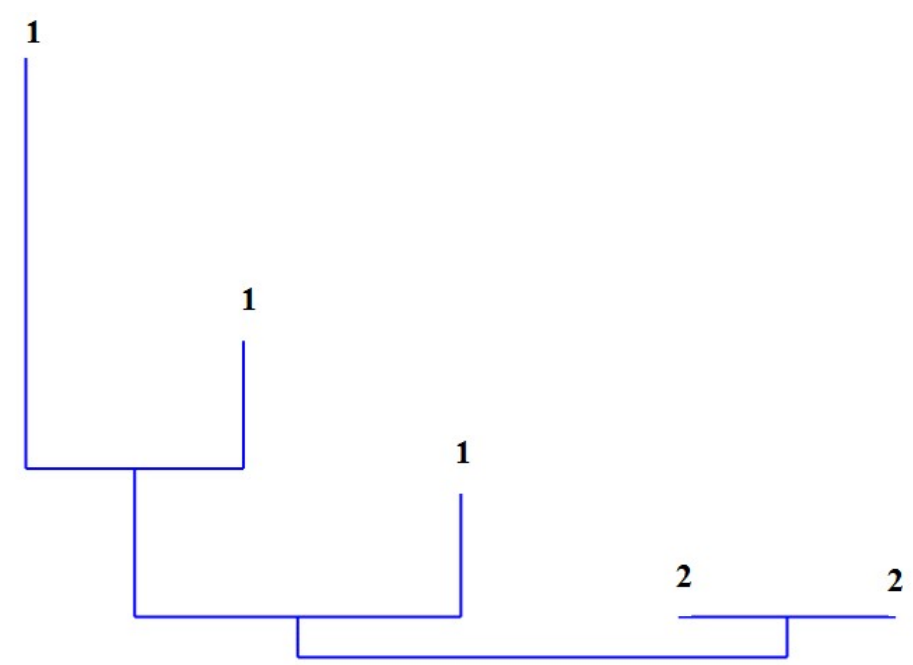

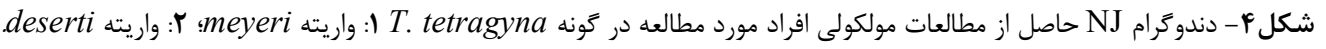

Figure 4. NJ Dendogram derived from molecular-based features of T. tetragyna 1: var. meyeri 2: var. deserti.

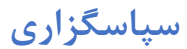

$$
\begin{aligned}
& \text { نويسندگان از داوران محترم مجله يافتههاى نوين علوم زيستى } \\
& \text { براى ارائه يُشنهادهاى سازنده تشكر مىنمايند. }
\end{aligned}
$$

\section{REFERENCES}

Assadi, M. 1988. Tamaricaceae, in Assadi, M. et al. (editors), Flora of Iran, vol. 1. Forests and Rangelands Research Institute, Tehran.

Arianmanesh, R., Mehregan, I., Assadi, M. \& Nejadsattari, T. 2016. Phylogenetic relationships of the genus Tamarix L. (Tamaricaceae) from Iran based on nuclear and plastid DNA sequences. Asian Journal of Conservation Biology 5: 45-50.

Arianmanesh, R., Mehregan, I., Assadi, M. \& Nejadsattari, T. 2016. Comparative morphology of the genus Tamarix (Tamaricaceae) in Iran. International Letters of Natural Sciences 60: 1-12.

Al-Qurainy, F., Khan, S., Nadeem, M. \& Tarroum, M. 2015. SCoT marker for the assessment of genetic diversity in Saudi Arabian date palm cultivars. Pakistan Journal of Botany 47: 637-643.

Alaimo, M. G., Gargano, M. L., Vizzì, D., \& Venturella, G. 2013. Leaf anatomy in Tamarix arborea var. arborea (Tamaricaceae). Plant Biosystems 147: 21-24.

Baum, B.R. 1967. Introduced and naturalized tamarisks in the United States and Canada (Tamaricaceae). Baileya 15: 1925.

Bretting, P.K. \& Widrlechner, M.P. 1995. Genetic markers and horticultural germplasm management. HortScience 30: $1349-1356$.

Brotherson, J.D. \& Winkel, V. 1986. Habitat relationships of saltcedar (Tamarix ramosissima) in central Utah. The Great Basin Naturalist 46: 535-541.

Brotherson, J.D. \& Winkel, V. 1986. Habitat relationships of saltcedar (Tamarix ramosissima) in central Utah. The Great Basin Naturalist 46: 535-541.

$$
\begin{aligned}
& \text { مطالعات مولكولى } \\
& \text { تست AMOVA تفاوت معنى دارى را در بين نمونههاى مورد } \\
& \text { مطالعه نشان داد. بر طبق نمودار NJ بر اساس نشانغر SCoT } \\
& \text { افراد به دو گروه مجزا تقسيم شدند كه اين كار تاييد كننده نتايج }
\end{aligned}
$$

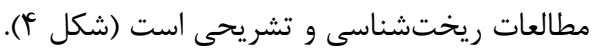
مطالعات در زونه Tamarix T. ramosissima و در ورنه Mirshekari et al., 2019; ) همخوانى داشت stricta (Marefatyan et al., in press 
Brown, S.M., Hopkins, M.S., Mitchell, S.E., Senior, M.L., Wang, T.Y., Duncan, R.R., Gonzalez-Candelas, F. \& Kresovich, S. 1996. Multiple methods for the identification of polymorphic simple sequence repeats (SSRs) in sorghum [Sorghum bicolor (L.) Moench]. Theoretical and Applied Genetics 93: 190-198.

Collard, B.C. \& Mackill, D.J. 2009. Start codon targeted (SCoT) polymorphism: a simple, novel DNA marker technique for generating gene-targeted markers in plants. Plant Molecular Biology Reporter 27: 86-93.

Daoyuan, Z., Dunyan, T., Juan, Z. \& Borong, P. 2003. Comparative anatomy of young branches of 16 species of Tamarix from China with reference to their ecological significance. Acta Botanica Yunnanica 25: 653-662.

Gaskin, J.F. 2003. Tamaricaceae. In flowering plants. Dicotyledons 5: 363-368.

Gaskin, J.F., \& Schaal, B.A. 2003. Molecular phylogenetic investigation of US invasive Tamarix. Systematic Botany 28: 86-95.

Gaskin, J.F., Ghahremaninejad, F., Zhang, D.-Y. \& Londo, J.P. 2004. A systematic overview of Frankeniaceae and Tamaricaceae from nuclear rDNA and plastid sequence data. Annales of the Missouri Botanical Garden 91: 401-409.

Gaskin, J.F. \& Kazmer, D.J. 2009. Introgression between invasive saltcedars (Tamarix chinensis and $T$. ramosissima) in the USA. Biological Invasions 11: 11211130.

Ghahremaninejad, F., Ataei, N. \& Nejad Falatoury, A. 2017. Comparison of angiosperm flora of Afghanistan and Iran in accordance with APG IV system. Nova Biologica Reperta 4: 73-97.

Hammer, O., Harper, D. \& Ryan, P.D. 2012. PAST: Paleontological Statistics software package for education and data analysis. Palaeontologia Electronica 4: 1-9.

Ijbari, H., Sheidai, M., Mehrabian, A.R., Noormohammadi, Z. \& Ghasemzadeh-Baraki, S. 2014. K-means clustering and structure analyses of genetic diversity in Tamarix L. accessions. Turkish Journal of Botany 38: 1080-1094.

Jensen, W.A. 1962. Botanical histochemistry. W.H.H. Freeman and Company, San Francisco and London.

Križman, M., Jakše, J., Baričevič, D., Javornik, B. \& Prošek, M. 2006. Robust CTAB-activated charcoal protocol for plant DNA extraction. Acta Agriculturae Slovenica 87: 427-433.

Marefatyan, S., Sheidai, M., Koohdar, F. \& Veisi, M. New subspecies within Tamarix ramossissma (Tamaricaceae) genetic and morphological evidence for publication. Genetica. in press.

Nawwar, M.A. \& Hussein, S.A. 1994. Gall polyphenolics of Tamarix aphylla. Phytochemistry 36: 1035-1037.
Olson, M.E., Gaskin, J.F. \& Ghahremaninejad, F. 2003. Stem anatomy is congruent with molecular phylogenies placing Hypericopsis persica in Frankenia (Frankeniaceae), comments on vasicentric tracheids. Taxon 52: 525-533.

Peakall, R.O.D. \& Smouse, P.E. 2006. GENALEX 6: genetic analysis in Excel. Population genetic software for teaching and research. Molecular Ecology Notes 6: 288295.

Peiyou, H. \& Rui-ru, G. 2004. Research on the extension of Tamarix shrubs resulted from development projects in arid area. Journal of Forestry Research 15: 45-48.

Podani, J. 2000. Introduction to the exploration of multivariate biological data. Backhuys Publishers.

Powell, W., Morgante, M., Andre, C., Hanafey, M., Vogel, J., Tingey, S. \& Rafalski, A. 1996. The comparison of RFLP, RAPD, AFLP and SSR (microsatellite) markers for germplasm analysis. Molecular Breeding 2: 225-238.

POWO. 2021. Plants of the World Online. Facilitated by the Roayal Botanic Gardens, Kew. http://www. plants of the world online.org (accessed 17 May 2021).

Sawant, S.V., Singh, P.K., Gupta, S.K., Madnala, R. \& Tuli, R. 1999. Conserved nucleotide sequences in highly expressed genes in plants. Journal of Genetics 78: 123 131.

Saidana, D., Mahjoub, M.A., Boussaada, O., Chriaa, J., Chéraif, I., Daami, M., Mighri, Z. \& Helal, A.N. 2008. Chemical composition and antimicrobial activity of volatile compounds of Tamarix boveana (Tamaricaceae). Microbiological Research 163: 445-455.

Schiman \& Czeika, H. 1964. Tamaricaceae, in Rechinger, K.H. (editor). Flora Iranica vol. 4. Akademische Druck- u. Verlagsanstalt, Graz-Austria, pp 1-17.

Sheidai, M., Mirshekari, R., Koohdar, F., Ijbari, H. \& Ghasemzadeh-Barakai, S. 2019. Biosystematic study in some Tamarix species in Iran. Genetika 51: 845-860.

Sheidai, M., Shagholi, T., Keshavarzi, M., Koohdar, F. \& Ijbari, H. 2019. Species delimitation and inter-specific gene flow in Tamarix L. (Tamaricaceae). Hacquetia 18: 313-322.

Sheidai, M., Teymoori, H., Noormohammadi, Z., Mehrabian, A.R., Koohdar, F. \& GhasemzadehBaraki, S. 2018. Species delimitation in the genus Tamarix: morphological and molecular data. Phytotaxa 343: 101-115.

Sheidai, M., Zanganeh, S., Haji-Ramezanali, R., Nouroozi, M., Noormohammadi, Z. \& Ghsemzadeh-Baraki, S. 2013. Genetic diversity and population structure in four Cirsium (Asteraceae) species. Biologia 68: 384-397.

Sheidai, M., Noormohamadi, Z. \& Sotodeh, M. 2006. Cytogenetic variability in several canola (Brassica napus) cultivar. Caryologia 59: 267-276.

How to cite this article:

Veisi, M., Sheidai, M. \& Koohdar, F. 2021. Morphological, anatomical and molecular study in two varieties of Tamarix tetragyna in Iran. Nova Biologica Reperta 8: 233-241. (In Persian).

ويسى، م.، شيدايى، م. و كوه دار، ف. . . أ. بررسى ريختشناسى، تشريحى و مولكولى دو واريته از گونه Tamarix tetragyna در ايران. يافتههاى نوين در علوم زيستى 1: 